\title{
СТРУКТУРА И ЭТАПЫ ПРОСТЕЙШЕГО КОММУНИКАТИВНОГО АКТА
}

\section{THE STRUCTURE AND STAGES OF AN ELEMENTARY ACT OF COMMUNICATION}

A. Dremov

Summary: This paper sets out the main results obtained by studying the problem, which we formulate as «image $A \rightarrow$ message $\rightarrow$ image $A 1$ ». This study, conducted in the framework of modern systemic linguistics, is intended to bring greater clarity to the understanding of the essence of the thought processes that occur in the minds of communication participants in the generation and perception of speech. The object of study is statements, the external form of which is the simplest proposition, and the internal form is premise (assertion), i.e. messages about phenomenons.

Keywords: message, simplest proposition, predication and nomination, premise (assertion), reasoning and conclusion.

\begin{abstract}
Дрёмов Алексей Федорович
К.филол.н., доцент, Московский государственный институт международных отношений (Университет) МИД России afdream@bk.ru

Аннотация: . В настоящей публикации излагаются основные результаты, полученные в ходе изучения проблемы, которую мы формулируем как «образ $A \rightarrow$ сообщение $\rightarrow$ образ $A_{1}$ ». Данное исследование, проводимое в рамках современной системной лингвистики, имеет целью внести бо́льшую ясность в понимание сути мыслительных процессов, протекающих в сознании участников коммуникации при порождении и при восприятии речи. Объект исследования: высказывания, внешней формой которых является простейшее предложение, а внутренней формой — суждение, т.е. сообщения о явлениях.
\end{abstract}

Ключевые слова: сообщение, простейшее предложение, предикация и номинация, суждение, рассуждение и умозаключение.
Д

ля того чтобы были понятны причины, по которым существо коммуникативного акта мы представляем как переход от образа, являющегося исходным рассуждения, к сообщению (шире к тексту), а затем от него к производному образу умозаключения, в идеале тождественному исходному, изложение придётся предварить кратким напоминанием содержания термина «суждение».

В логике под суждением понимается основная форма мысли или «мысль, содержащая утверждение о наличии в действительности некоторого положения дел» и выражаемая «в языке с помощью повествовательных (декларативных) предложений» [1, с. 12-13]. Из этого и других определений суждения (см., напр., [7, с. 503]) следует, вопервых, то, что суждение - это мысль высказанная, т.е. объективированная с помощью речевых знаков, одним из которых называется «предмет мысли», или субъект, а другим - «то, что утверждается или отрицается относительно предмета мысли», т.е. предикат. Во-вторых, из этого определения также следует, что конкретное суждение - это высказанная мысль продуцента, инициатора коммуникативного акта, позиция которого как лица, выражающего суждение, отражена в наименованиях не только терминов суждения, но и членов предложения и сообщения: субъект - подлежащее - тема; предикат сказуемое - рема. (Понятно, что гомологичность данных понятий не может быть основанием для их отождествления.)

Теперь от логики перейдём к языкознанию, а конкретно - к системной лингвистике.

В современной системной лингвистике, принципы которой были залолжены В. фон Гумбольдтом, развиты и дополнены А.А. Потебнёй, И.И. Срезневским, И.А. Бодуэном де Куртенэ, А.А Шахматовым, а в XX столетии были существенно углублены Г.П. Мельниковым (см. библиографию, напр., в [11]), разработавшим, в частности, такую новую научную дисциплину, как системология [9], ставшую методологической основой данного направления языкознания, содержащееся в сообщении суждение «понимается как такое возбуждение двух психических образов, представляющих элементы знания в сознании субъекта, один из которых - предиканд, подвергается воздействию со стороны другого - предикатора и видоизменяется, преобразуется в результате этого воздействия, превращаясь в уточнённое, обновлённое знание, в предикат' 1 , а предикацией называется сам процесс такого преобразования предиканда в предикат с по-

Термины «предиканд» и «предикатор» соответствуют общепринятым «субъект» и «предикат». Что же касается вывода из суждения, названного Г.П. Мельниковым «предикатом» и называемого нами антецедентом, то его существования не замечают ни логики, ни тем более лингвисты.

В этом отношении суждение подобно энтимеме, в которой опущено заключение. 
мощью предикатора» [10, с. 57 - 58] (курсив автора. А.Д.). Насколько нам известно, это последняя редакция предложенных Г.П. Мельниковым дефиниций суждения и предикации, однако суть происходящего в сознании реципиента при восприятии сообщения, была им описана ещё в 1970-х годах [8; 9, с. 294 - 295].

Данное определение суждения через истолкование предикации как преобразования одного элемента знаний, называемого в сообщении знаками темы, с помощью другого, называемого знаками ремы, и получение вследствие этого нового смысла - выводного, производного знания, которому в высказывании, содержащем суждение, не соответствуют ни знаки темы, ни знаки ремы, прямо восходит к выводам В. фон Гумбольдта о природе того, что он назвал «актом самостоятельного полагания через соединение (синтез)», «который, как это доступно лишь для подлинно творческого акта духа, производит из двух связуемых элементов третий, где оба первые перестают существовать как отдельные сущнолсти» [3, с. 197], и «создаёт нечто такое, что не содержалось ни в одной из сочетающихся частей как таковых» [3, с. 107].

Следовательно, предикация в мельниковской трактовке есть не что иное, как понимание реципиентом содержащегося в сообщении суждения, т.е. синтез нового смысла из смыслов, выражаемых знаками темы и ремы, в результате чего в сознании реципиента «создаётся, то есть реально полагается (актом мысли) как самостоятельно существующее, нечто новое» [3, с. 198].

Однако так в логике определяется не суждение, а умозаключение - мыслительное действие, «в результате которого новое знание получатся логически, без обращения непосредственно к опыту, из предшествующих знаний» $[7$, с. 86, с. 551$]$.

Сказанным перечень выявленных расхождений, носящих, как мы видим, не только терминологический характер, не ограничивается. Но мы не будем продолжать его, поскольку гораздо важнее разобраться в причинах данных разногласий, тем более что необходимые для этого предпосылки у нас имеются.
По нашему мнению, суть проблемы коренится в том, что выражаемое продуцентом суждение как в логике, так и в лингвистике рассматривается как объект восприятия реципиента, вследствие чего процессы, протекающие в сознании продуцента, предшествующие высказыванию и наполняющие его смысловым содержанием, были обойдены вниманием. Это и стало отправным моментом для наших изысканий, материалом для которых послужили сообщения, имеющие форму пропозиции, понимаемой с современной системной лингвистике как ассоциация по смежности простейшего предложения и суждения: Солние село; Температура повышается; Костёр гаснет; студент читает; Травка зеленеет, Солнышко блестит; чай остывает и т.п.

Начать, по-видимому, следует с того, что конкретное, высказанное, суждение - это не просто данность, с которой имеет дело реципиент, а произведение, продукт мыслительной деятельности продуцента, причём такой же творческой, как и синтез, о котором говорилось выше, и требующей от него не меньше мыслительных усилийㄹ.

Любое суждение, будучи законченной мыслью, есть результат рассуждения, понимаемого как такое индуктивное мыслительное действие автора этого произведения, вследствие которого конкретный, текущий, оперативный образ объекта - образ $A$, выполняющий в рассуждении функцию его исходного члена - антецедента, «аналитизируется», т.е. подобно сложному веществу разлагается, расчленяется на два более простых: 1) обобщённый статичный индивидный образ этого объекта или образ вида, в который данный объект входит как элемент, - образ S, выполняющий в суждении функцию субъекта суждения и налзываемый, а точнее - напоминаемый ${ }^{3}$ знаками темы либо самоочевидный и потому в речи опускаемый ${ }^{4}$, и 2) такой же обобщённый и статичный индивидный либо видовой образ свойства, проявляемого этим объектом в описываемом явлении, - образ Р, выполняющий в суждении функцию предиката и всегда называемый (напоминаемый) в речи знаками ремы. В коммуникативном аналитизме - расчленённости сообщения на тему и рему, в частности интонационной, отражено мысленное расчленение целостного

\footnotetext{
2 «Как сердцу высказать себя? / Другому как понять тебя? / Поймёт ли он, чем ты живёшь? / Мысль изречённая есть ложь» (Ф. И. Тютчев. Silentium).

3 Если предикация инициирует умозаключение для получения «нового» (актуально значимого) знания, то номинация инициирует воспоминание «старого» знания. Основная функция номинации в речи состоит именно в напоминании уже имеющегося знания.

4 Когда в речи употребляются так наз. нерасчленённые высказывания с «нулевой темой», или высказывания с «комплексной ремой», то в той функции, для выполнения которой в суждении служит образ, напоминаемый знаками темы расчленённого высказывания, а значит и в функции субъекта суждения, по отношению к которому образ, напоминаемый знаками нерасчленённого высказывания, выступает в качестве предиката, продуцентом используются коммуникативно априорный гештальт «я-здесь-сейчас-(говорю)» или его конверсивы [4, с. 53 - 63]; напр.: \{В том месте и в то время, где и когда я (это) говорю, т.е. здесь и сейчас\} — Зима! / Холодно. / Светает. / Ни звука. / Шёпот, робкое дыханье... / Птицы летят. / Мороз и солнце; день чудесный! / Погасло дневное светило и т. п.

Это значит, что без темы, как и без ремы, сообщения не может быть в принципе, ибо нет и не может быть суждения, а значит и умозаключения без субъекта или предиката, не говоря уже о невозможности рассуждения без его исходного члена - основания, т.е. образа-антецедента. Сообщения без темы, как и суждение без субъекта, если бы они существовали, можно было бы сравнить с задачей, без условия.
} 
исходного образа суждения - антецедента на субъект и предикат суждения. Расчленение высказывания может быть закреплено в языке на синтаксическом и на морфологическом уровне в виде двух главных членов простейшего предложения - подлежащего и сказуемого, функции которых выполняют соответственно имя $\left(\mathrm{N}_{0}\right)$ и личная форма глагола $\left(\mathrm{V}_{\mathrm{f}}\right)$ - «формальные выразители предикации» [9, с. 297].

Таким образом, суть рассуждения как аналитического, индуктивного мыслительного действия заключается в переходе от конкретного динамичного образа объекта к его абстрактному статичному образу, в результате чего, в частности, осуществляется опознание объекта и его свойства и подведение их под понятия или категории.

Иными словами, в процессе рассуждения в нашем сознании совершается «качественный скачок» - переход от чувственных форм отражения действительности к рассудочным формам, что равнозначно переходу от интуитивного знания как знания непосредственного, получаемого в результате прямого воздействия объекта на органы чувств, и, следовательно, основанного на невербальном, внеязыковом мышлении, к знанию дискурсивному - опосредствованному, логическому, получаемому в результате рассуждения, опирающемуся на предшествующий опыт и, следовательно, на «оязыковленное» (Бодуэн), структурированное с помощью языка мышление.

Что касается умозаключения, то и оно является актом мышления, но, так сказ., зеркально симметричным рассуждению, его конверсивом и коррелятом. Умозаключение осуществляется с целью понимания выраженного сообщением суждения и представляет собой элементарное дедуктивное мыслительное действие получателя сообщения - реципиента. Вследствие этого действия названный (напомненный) в речи знаками темы индивидный или видовой образ объекта - образ S, выполняющий в умозаключении функцию субъекта, превращается в результате синтеза с названным (напомненным) знаками ремы индивидным или видовым образом свойства - образом $P$, выполняющим в умозаключении функцию предиката, в целостный связный динамичный текущий образ объекта — образ $A_{1}$, являющийся выво- дом из умозаключения, который мы называем консеквентом. Иными словами, посредством умозаключения реципиент в той или иной мере постигает замысел продуцента. Это также значит, что суждение, являющееся продуктом мыслительной деятельности продуцента, реципиентом воспринимается как объект мыслительной деятельности.

Таким образом, суть умозаключения как синтетического, дедуктивного мыслительного действия реципиента, совершаемого на заключительном этапе коммуникативного акта, во время которого в сознании реципиента из двух известных элементов знания (образов), напомненных ему продуцентом знаками темы и ремы, формируется новый образ, «новое знание» ${ }^{5}$, заключается в «восхождении от абстрактного к конкретному», т.е. в превращении обобщённого статичного индивидного, видового или родового образа в текущий, оперативный образ описываемого объекта.

Следовательно, при умозаключении наше сознание тоже, как и при рассуждении, совершает «качественный скачок», но теперь он осуществляется в обратном направлении: в результате умозаключения мы переходим от рассудочных форм отражения действительности - понятий и категорий, к чувственным формам - восприятию и ощущениям, т.е. впечатлениям. Посредством умозаключений мы переходим от дискурсивных, логических, «оязыковленных» знаний к таким знаниям, которые если и не тождественны, то по крайней мере подобны знаниям, получаемым при прямом воздействии объектов на наши органы чувств, и, стало быть, опирающимся на невербальное, внеязыковое, образное мышление 6 .

В результате восприятия сообщения, благодаря напомненным знаками темы и ремы образам - S и $P$, являющимся В умозаключении исходными, реципиент формирует в своём сознании конкретный образ - актуальный образ объекта, явление которое ему не было дано в ощущениях, и благодаря этому он может, так сказ., «заочно стать очевидцем» описываемого явления, т.е. вообразить это явление, увидеть его мысленно.

На основании вышеизложенного мы пришли к следу-

5 «Новое знание» - это необязательно знание, в корне меняющее какие-л. представления реципиента о действительности. Главное в выводном знании - это то, что оно значимо актуально и поэтому может рассматриваться реципиентом исключительно с точки зрения его утилитарности или функциональности, а не существенности. Вместе с тем ясно, что всякое производное знание всегда является для реципиента новым в том смысле, что оно не называется продуцентом прямо, и поэтому никогда не даётся реципиенту в высказанном суждении в «готовом» виде.

6 Это, по-видимому, одна из иллюстраций того, каким образом язык, будучи семиотической системой, реализует присущие ему функции - является не только средством обеспечения коммуникации, но и инструментом познания действительности, хранения и передачи информации. Вербальные знаки выступают для нас репрезентантами объектов и их свойств, и мы опосредствованно, минуя фазу чувственного отражения, можем, благодаря языку, отобразить в своём сознании то, чего сами физически воспринимать не могли. Но они являются для нас субститутами вещей и их свойств лишь тогда, когда, воздействуя на наши органы чувств, возбуждают в нашем сознании образы, аналогичные тем, которые возникают при непосредственном восприятии самих вещей. 
ющим выводам.

1. С учётом того, что структура связей и отношений элементов сложного образа тоже имеет образную природу и в русском как флективном языке закреплена на уровне формального синтаксиса в значениях реляционных морфем [9, с. 292 - 294], мы можем представить все семь этапов коммуникативного акта - от порождения сообщения о таком наблюдаемом или представляемом продуцентом объекте, как, напр., «квадрат, который (здесь и сейчас) обретает чёрный цвет» ${ }^{7}$, до понимания реципиентом этого сообщения - В виде обобщающей схемы, для чего обозначим 1) конкретные образы данного объекта - $A$ и $A_{1}-$ символом ш, 2) S суждения, понятие «квадрат», символом $\square$, 3) $P$ суждения, понятие «чернеть», символом •, 4) акт рассуждения (анализ антецедента) и акт умозаключения (синтез консеквента) - стрелками; 5) предикативную, т.е. причинную, генетическую, связь напоминаемых знаками темы и ремы понятий (образов) знаком тире; 6) различие генезиса исходного образа рассуждения и производного образа умозаключения отобразим в различии формы скобок: простыми скобками обозначим образ-антецедент, а фигурными - образ-консеквент.

Таблица 1

Основные этапы элементарного коммуникативного акта

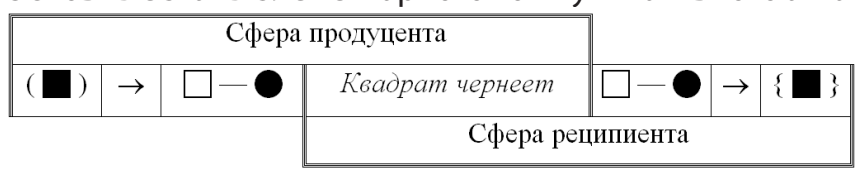

Очевидно, что критерием успешности коммуникативного акта служит степень подобия вывода, образа-консеквента $A_{1}$, сформированного реципиентом в результате восприятия сообщения, образу-антецеденту $A$, ставшему основанием для рассуждения продуцента и поводом для коммуникации. Ясно, что она (успешность) определяется целым рядом факторов, но в первую очередь зависит от того, в какой мере коммуниканты гомотетичны в социальном, культурном и интеллектуальном отношении.

2. Данная схема позволяет также увидеть, что денотатом речевого знака, действительно, является не реальный, «явленный», объект (и/или его свойство), а его перцептивный образ - результат воздействия объекта на органы чувств субъекта познавательной деятельности.

3. Любое конкретное суждение, в частности о наблюдаемом объекте, есть результат рассуждения, понимаемого в духе В. Гумбольдта как «акт самостоятельного полагания через расчленение (анализ) $»^{8}[3$, с. 54].

4. Суждение как конкретное высказывание, безусловно, двучленно: «S ecmь $P$ », но на уровне смыслов, т.е. как форма мысли, оно трёхчленно и для адресанта, и для адресата сообщения: « $A \rightarrow S-P »$ для первого, «S-P $\rightarrow A_{1}$ » для второго.

5. Сообщение о явлении - это целостное связное речевое произведение, создаваемое его автором (продуцентом) на основе простейшего предложения и суждения с целью возбуждения в сознании собеседника (реципиента) умозаключения, в результате которого он может, по мнению автора сообщения, силой своего «творческого духа» воображения сформировать образ-консеквент, подобный исходному образу суждения - образуантецеденту.

\section{ЛИТЕРАТУРА}

1. Бочаров В.А., Маркин В.И. Основы логики: Учебник. — М. : ИНФРА-М, 1998. — 296 с.

2. Васильев В. В. Разум и рассудок. — Большая энциклопедия Кирилла и Мефодия, 000 «Кирилл и Мефодий», 2002. — 2 CD-ROM.

3. Гумбольдт, Вильгельм фон. Избранные труды по языкознанию: Пер. с нем. — М. : Прогресс, 1984. — 400 с.

4. Дрёмов А.Ф. Роль падежей русского языка в обеспечении связности и компрессии текста. Дис. ... канд. филол. наук. - М. : УдН, 1984. - 188 с.

5. Дрёмов А.Ф. Минимальный состав, структура и иерархия элементов предикативного акта. // Филологические науки. Сб. науч. тр. № 1 (16). — М. : МГИМ0, 1999. - С. $129-134$.

6. Дрёмов А.Ф. Номинация в свете системных воззрений на природу языкового знака (некоторые теоретические уточнения). //Филологические науки. Сб. науч. тр. № 2 (17). — М. : МГИМ0, 2000. - С. $33-48$.

7. Кондаков Н.И. Логический словарь. — М. : Наука, 1971. — 656 с.

8. Мельников Г.П. Сущность предикации и способы её языкового выражения. // Инвариантные синтаксические значения и структура предложения. — М. : Наука, 1968. - С. $116-125$.

7 Использование данного примера обусловлено техническими причинами.

8 Данный термин образован нами по аналогии с термином В. Гумбольдта «акт самостоятельного полагания через соединение (синтез)». 
9. Мельников Г.П. Системология и языковые аспекты кибернетики. - М. : Сов. радио, 1978. - 368 с.

10. Мельников Г.П. Системная типология языков. Синтез морфологической классификации языков со стадиальной. Курс лекций. — М. : РУдН, 2000. - 96 с.

11. Мельников Г.П. Системная типология языков: Принципы, методы, модели / Отв. ред. Л.Г. Зубкова. — М. : Наука, 2003. — 395 с.: ил.

12. Соловьёв В.С. Разум — рассудок. Большая энциклопедия Кирилла и Мефодия — 000 «Кирилл и Мефодий», 2002. — 2 CD.

13. Философский энциклопедический словарь. В 5 томах. Глав. ред. Ф.В. Константинов. — М. : Сов. энциклопедия. — 1960 - 1970.

○ Дрёмов Алексей Федорович (afdream@bk.ru).

Журнал «Современная наука: актуальные проблемы теории и практики»

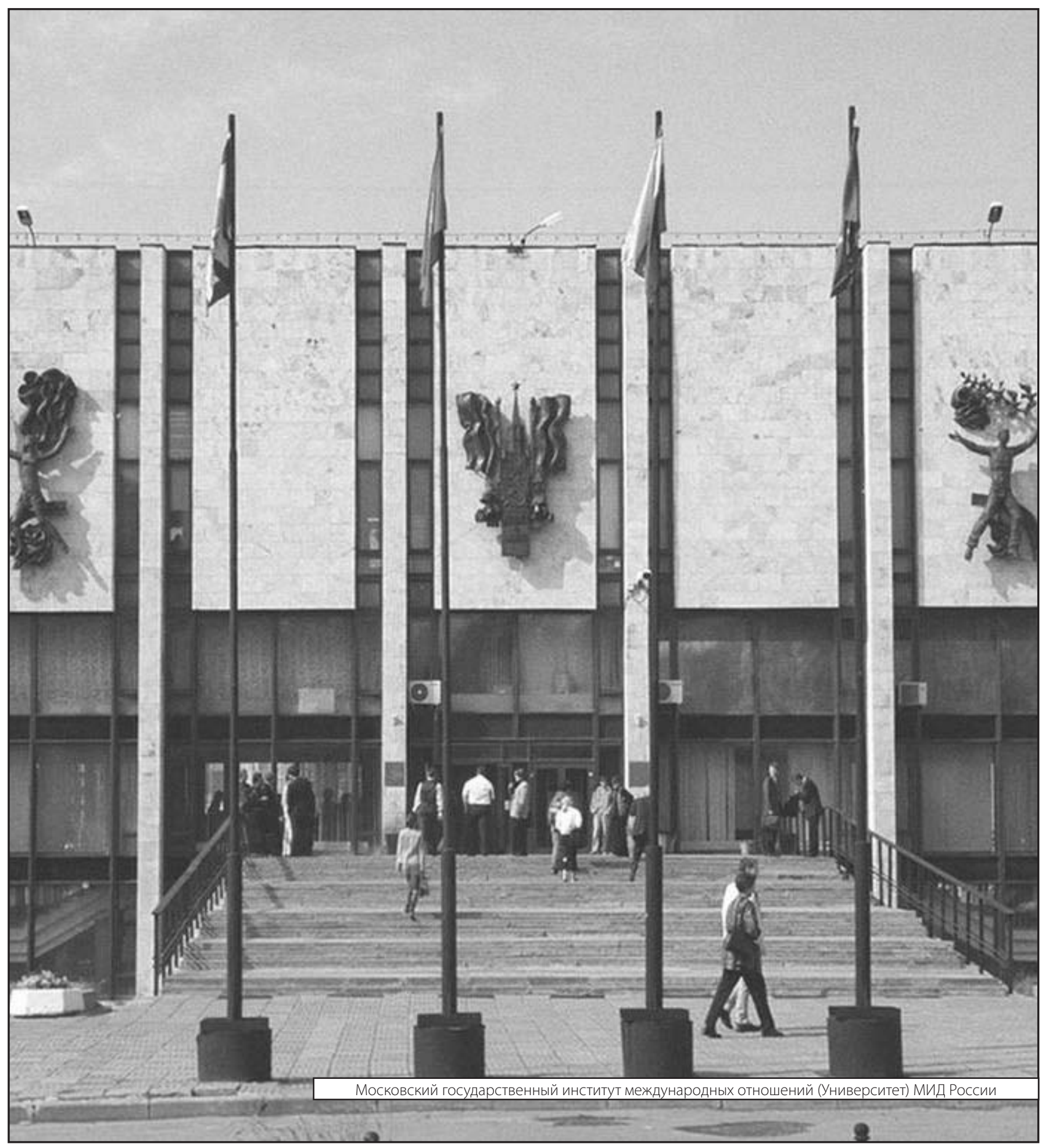

